\title{
REGIONAL ANALYSIS OF CROP AND NATURAL VEGETATION IN WEST AFRICA BASED ON NDVI METRICS
}

\author{
Leroux Louise, Bégué Agnès, Lo Seen Danny \\ UMR TETIS, CIRAD, 500 rue Jean-François Breton, 34093, Montpellier, France
}

\begin{abstract}
In West Africa, rainfall variability dynamics are often considered as the major driver of vegetation production. Land use shifts have also to be taken into account when analyzing changes in vegetation production. To study how land use changes may impact vegetation response along a climatic gradient, we used three MODIS NDVI metrics time series (2000-2012) and a land cover map from MODIS Land Cover product. We performed a trend analysis and analyzed temporal profiles of the three metrics according to three climatic zones (Sahelian, Sudanian and Guinean zones). Our results indicate differences in NDVI values of Croplands and Natural Vegetation and that these differences are in connection with climatic zones. In the Sahelian zone Croplands tend to have higher values than Natural vegetation, whereas the opposite is observed for the Sudanian and Guinean zones.

These results could help improve the interpretation of vegetation trends in a context of climate and land management shifts.
\end{abstract}

Index Terms - West Africa, NDVI metrics, Cropland, Natural vegetation, Trend analysis, MODIS

\section{INTRODUCTION}

West Africa is a region where rainfed agriculture is a major component of food production. However, mainly because of high climate variability that leads to high fluctuations in crop productivity, West Africa remains a region where local populations are subject to chronic food insecurity.

In this context, remote sensing observations provide timely, repetitive and synoptic information on vegetation development [1]. Since the beginning of the 1980s and the arrival of the NOAA AVHRR sensor, and with the launch of the MODIS sensor in the early 2000s, there has been an increase in vegetation monitoring studies at coarse scale in West Africa both in terms of inter-annual variability and trends[2-4].

In addition, several organizations that monitor food security (e.g. FEWSNET or AGRHYMET) often use data from remote sensing as indicators of crop production. These monitoring systems are principally based on Vegetation Indices such as the NDVI (Normalized Difference Vegetation Index) derived from coarse to moderate-scale satellites because it is considered as reliable indicators of vegetation conditions and a proxy of biomass production at regional scale [5].

To interpret NDVI trends, climate (changes in amount, spatial and temporal distribution and intensity of rainfall or temperature) is usually considered as the main determinant. However, other factors mostly related to human-induced land use and land management changes must also be considered [6], [7].

That is why, in sub-Saharan West Africa, an in-depth knowledge of the vegetation response is essential when analyzing vegetation production and especially crop production trends. Thus, the aim of this study was to illustrate how land use changes may impact vegetation response along a climatic gradient. To achieve this, vegetation production was compared spatially (following climatic zones) and temporally (between 2000 and 2012) through different NDVI metrics and according to broad land cover classes (Cropland and Natural Vegetation).

\section{MATERIALS AND METHODS}

\subsection{Study Area}

West Africa (latitudes $4^{\circ}$ to $18^{\circ}$ North and longitudes $-18^{\circ}$ to $16^{\circ}$ East; Fig. 1 ) is a region characterized by a broad

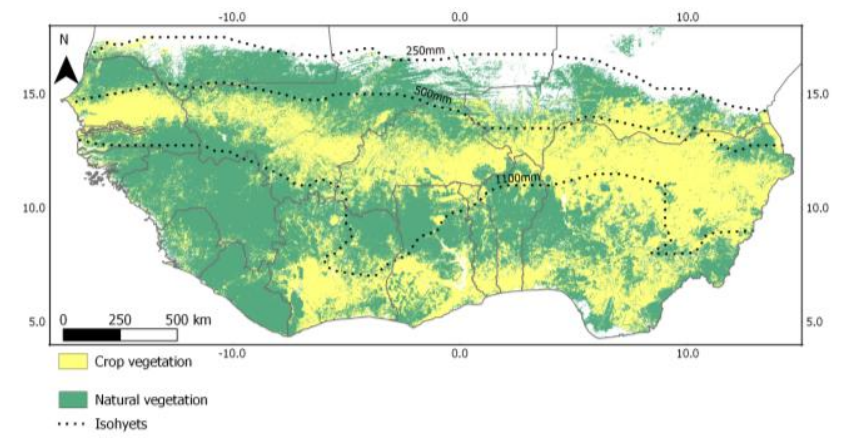

Figure 1. West Africa Cropland and Natural vegetation map and climatic zonation. Land cover classes are extracted from the MODIS Land Cover Product and climatic zones from the TRMM 3B43 product. 
climatic gradient from North (Sahelo-Sudanian climate with one rainy season) to South (Guinean climate with two rainy seasons) controlled by the dynamics of the Intertropical Convergence Zone (ITCZ) [8]. Consequently, due to rainfall which follows a latitudinal gradient, the regional vegetation patterns could be stratified into three main ecoregions that are the Sahelian acacia savanna, just south of the Sahara, the Sahelo-Sudanian savanna at intermediate latitudes and the Guinean forest in the South [9].

\subsection{Data}

16-days NDVI MODIS (MOD13Q1) time series at 250m spatial resolution for the period 2000-2012 were used. The data were preprocessed by (i) reconstructing 16-days data by a linear interpolation of the raw data based on the DOY (Day of the Year) band, (ii) applying a Savitzky-Golay filter to reduce the noise and improve the quality of the NDVI time series [10] and (iii) aggregating 16-days data to annual data.

The MODIS Land Cover Product (MCD12Q1) at spatial resolution of 500-m was employed to obtain a mask of the cropland domain and the natural vegetation domain. The land cover map contained 17 classes. Classes were aggregated to obtain a two-classes map: Cropland (class 12 and class 14) - Natural Vegetation (all classes minus class 12 and class 14).

West Africa was divided into three eco-climatic zones (Fig.1) delimited by isohyets obtained from average annual rainfall data derived from the TRMM 3B43 product: (i) the Sahelian (250-500 mm year-1 ), (ii) Sudanian (500-1100 mm year $\left.{ }^{-1}\right)$ and (iii) Guinean $\left(>1100 \mathrm{~mm}\right.$ year $\left.^{-1}\right)$ [11].

\subsection{Methods}

Three NDVI-derived measures (metrics) were computed to characterize vegetation temporal pattern (Fig.2): (i) the annual integrated NDVI (CumNDVI), (ii) the annual maximum NDVI (MaxNDVI) and (iii) the annual range of the NDVI (RangeNDVI) [12].

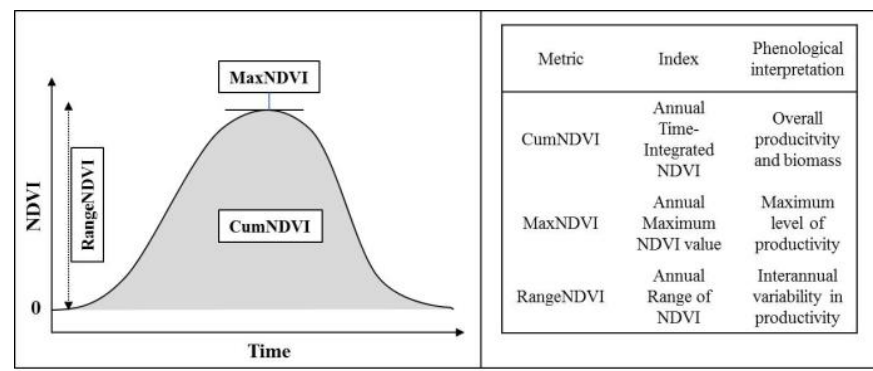

Figure 2. Diagram with definition of the three NDVI-derived metrics

Vegetation trends between 2000 and 2012 were performed using an Ordinary Least Square Regression within the Cropland and Natural Vegetation masks based on
NDVI metrics time series. Slopes and pvalues (statistically significant at the $10 \%$ threshold) were classified to quantify the direction and the magnitude of the overall trend. Trend analyses were carried out for each three climatic zones.

The Cropland/Natural Vegetation CumNDVI difference was mapped for the whole of West Africa. To do that, the annual averaged CumNDVI (2000-2012) was computed for each land cover mask. The mean CumNDVI values were then assessed within a moving window of $41 \times 41$ pixels in order to have a spatial redistribution of the information. Finally, we subtracted the two new land cover masks to obtain the difference map.

\section{RESULTS AND DISCUSSION}

About $70 \%$ of pixels in West Africa have no significant trends. Most of the significant trends are principally in the Sahelian and Sudanian zones that show an increase in vegetation production. The Guinean zone mainly has no significant trends that could be due to persistent cloud cover in that region (Fig.3). The analysis according to land cover classes reveals that areas of no significant trends are more important for Natural Vegetation, with an increase along the climatic gradient (Fig.4). In addition, a fraction larger for Natural Vegetation pixels than for Cropland Vegetation pixels have positive trends (i.e. $\sim 23 \%$ of Cropland pixels with positive trends and $\sim 31 \%$ for Natural Vegetation) in the Sahelian zone. For the Sudanian and Guinean zones, the proportion of pixels with positive or negative trends is almost the same for both Natural and Cropland Vegetation (Fig.4).

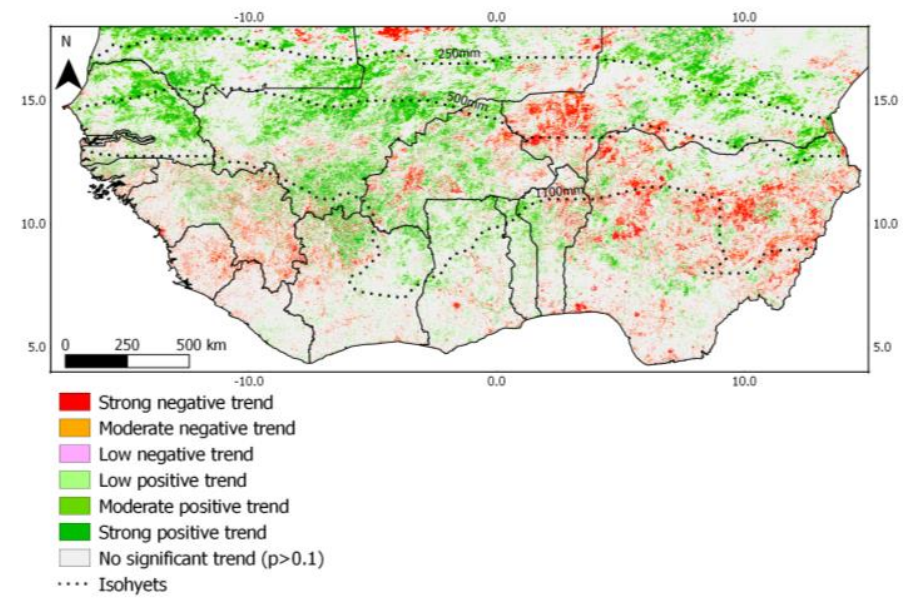

Figure 3. Overall trends in vegetation production over the period 20002012 based on MODIS CumNDVI time series.

The spatio-temporal pattern of the NDVI metrics shows that vegetation production is highly related to latitude and consequently to rainfall (Fig.5). For both Natural Vegetation and Cropland Vegetation, the three metrics values are highest for the Guinean zone and are almost two fold those 
of the Sahelian zone. Our findings are in agreement with [8] who found that the Sahelian and sub-Sahelian regions provide a high North-South gradient in both rainfall and vegetation phenology. It can be noted that the three NDVI metrics have a positive trend in the Sahelian zone, a stable trend in the Sudanian zone and a slight negative trend in the Guinean zone, confirming the findings of [11]. In addition, the three NDVI metrics have an inter-annual variability higher for the Sahelian zone than for the Sudanian and Guinean zones, particularly for the MaxNDVI and RangeNDVI. The NDVI is related to the amount of green biomass but saturates when the vegetation is dense[13]. Consequently, in the Sahelian zone where soils are covered by low vegetation, an increase in rainfall will lead to higher variability of MaxNDVI values. The Sudanian zone, a transition zone between the Sahelian and Guinean zones, is characterized by a mix of herbaceous and woody vegetation [9]. Little variability is observed for the MaxNDVI in this region. This could be due to a saturation effect of the NDVI for areas with higher density vegetation and a higher interannual variability of Minimum NDVI values may explain the RangeNDVI variability. A high inter-annual variability of the RangeNDVI is also observed for the Guinean zone despite the fact that the MaxNDVI remains stable over time. For this zone, in addition to the saturation effect for forest areas, the cloudiness may have an impact on the variability of Min NDVI values and leads to the variability of the RangeNDVI.

\section{a) Cropland}

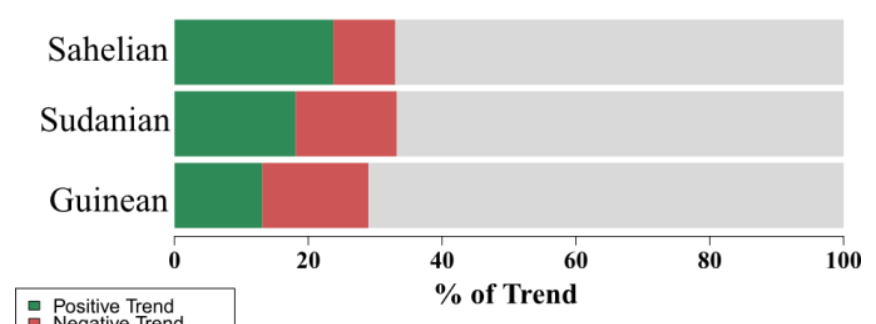

b) Natural Vegetation

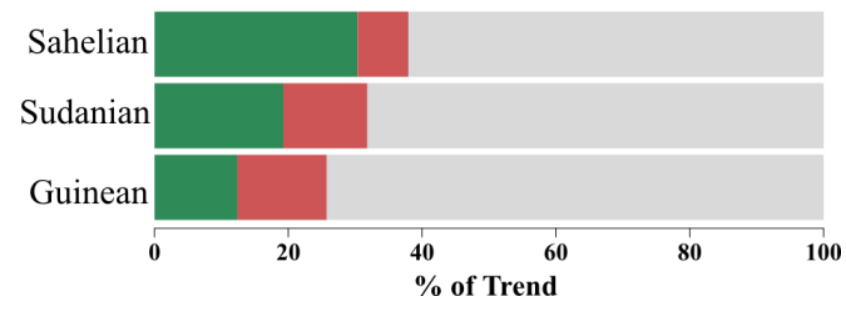

Figure 4. Pixels distribution of trend for a) Cropland and b) Natural vegetation), inside each climatic zone.

The analysis of the difference map (Fig.6) and the temporal profiles of metrics reveal that Cropland NDVI values (Max and CumNDVI) are higher than those of Natural Vegetation in the Sahelian zone but lower in the Sudanian and Guinean zones with a more significant difference for the CumNDVI metric (Fig.5a and Fig.5b). The same tendency was observed previously by [14] in a Sahelian area of Niger and recently by [15] in South-Mali concerning the SOS (start-of-season). This is also in agreement with the study of [16] in the Bani catchment in Mali. Authors found with Landsat images that cropped areas in the Sahelian zone had a higher annual NDVI than savannas areas. For the Sahelian zone, we can assume that the positive trend of the Natural Vegetation observed in Fig. $4 \mathrm{~b}$ could be due to a land cover change. For instance, the cultivation of new land may lead to an increase in vegetation productivity and thus to the positive trend. There is however no significant difference between Crop and Natural Vegetation for the RangeNDVI metric (Fig.5c) meaning that the gap between Crop and Natural Vegetation remains fairly constant over time. These differences between Cropland and Natural Vegetation nevertheless still need to be validated especially by the use of high resolution images. In addition, it has to be pointed out that the three metrics were computed for each pixel and then aggregated per land use classes and climatic zones. Consequently, this approach would mask the within class variability due to soils, morphology, human impact or latitude [17] but also the land cover changes during the period. a) MaxNDVI

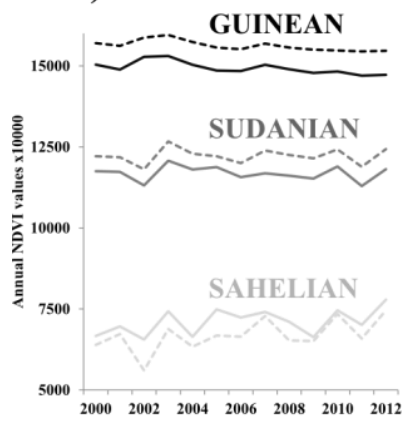

c) RangeNDVI

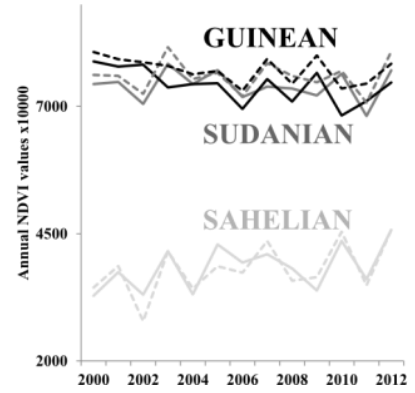

b) CumNDVI
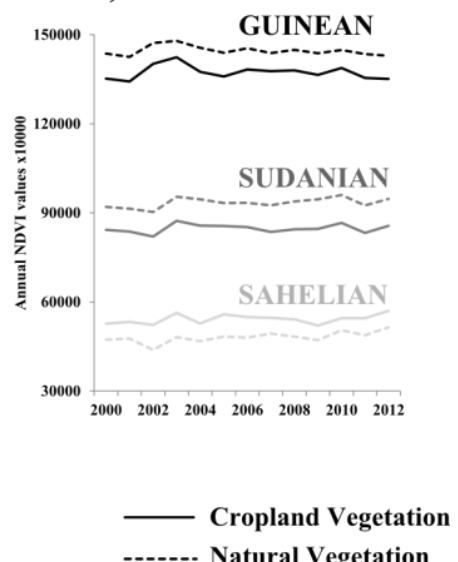

Figure 5. Time series of the Cropland and Natural vegetation NDVI metrics between 2000 and 2012 for the three climatic zones: a) MaxNDVI, b) CumNDVI, c) RangeNDVI.

\section{CONCLUSION}

Analyses of NDVI trends in sub-Saharan West Africa were widely used since the beginning of the 1980 s to understand vegetation dynamics. Many studies have put 
forward that vegetation trends are mainly controlled by rainfall [e.g. [2], [7]]. However too few studies take into consideration how land use / land cover changes may impact vegetation response given the climatic constraints.

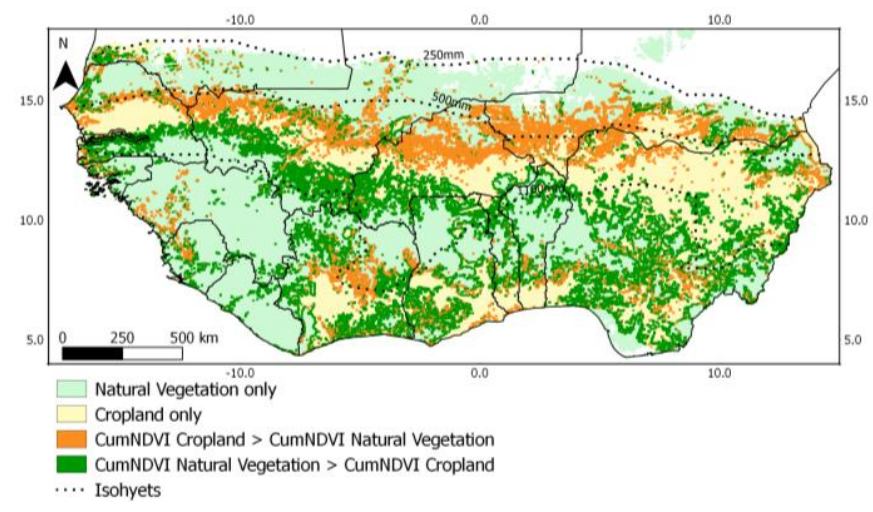

Figure 6. Map of the signed differences between Cropland and Natural vegetation CumNDVI (averaged between 2000 and 2012).

As expected, our study shows that rainfall is a driver of vegetation. However, we also demonstrated that the vegetation response for two classes (Cropland and Natural Vegetation) vary along a climatic gradient. In concrete terms this means for instance that a crop expansion at the expense of natural vegetation in the Sahelian zone would probably lead to an increase in NDVI values and thus to a positive vegetation trends, whereas the opposite effect would be expected in the Sudanian and Guinean zones.

Consequently, in a context of food security, NDVI time series can be used to assess changes in crop production. At the regional scale, vegetation trends can mainly be explained by rainfall variability. However, due to the complexity of the relationships between climate and land use or land management shifts, further analysis at local scale have to be considered to explain crop vegetation trends. In that sense, studies at regional scale can be used to pinpoint areas of marked changes in order to set up more detailed studies about the factors explaining vegetation trends.

\section{ACKNOWLEDGEMNTS}

This work was supported by CIRAD (L. Leroux fellowship) and by the Project CNES-TOSCA "Dynafrique". Thanks to the MODIS team for sharing MODIS products.

\section{REFERENCES}

[1] M. Meroni, et al, "Early detection of biomass production deficit hot-spots in semi-arid environment using FAPAR time series and a probabilistic approach," Remote Sensing of Environment, vol. 142, pp. 57-68, Feb. 2014.

[2] S. M. Herrmann, A. Anyamba, and C. J. Tucker, "Recent trends in vegetation dynamics in the African Sahel and their relationship to climate," Global Environmental Change, vol. 15, pp. 394-404, 2005.
[3] A. Anyamba and C. J. Tucker, "Analysis of Sahelian vegetation dynamics using NOAA-AVHRR NDVI data from 1981 2003," Journal of Arid Environments, vol. 63, pp. 596614, 2005.

[4] C. Dardel, et al, "Re-greening Sahel: 30years of remote sensing data and field observations (Mali, Niger)," Remote Sensing of Environment, vol. 140, pp. 350-364, Jan. 2014.

[5] X. Zhang, et al, "Monitoring vegetation phenology using MODIS," Remote Sensing of Environment, vol. 84, pp. 471-475, 2003.

[6] M. A. White, "A global framework for monitoring phenological responses to climate change," Geophysical Research Letters, vol. 32, no. 4, 2005.

[7] K. Rasmussen, et al, "Explaining NDVI trends in northern Burkina Faso," Geografisk Tidsskrift-Danish Journal of Geography, vol. 114, no. 1, pp. 17-24, Jan. 2014.

[8] X. Zhang, "Monitoring the response of vegetation phenology to precipitation in Africa by coupling MODIS and TRMM instruments," Journal of Geophysical Research, vol. 110, no. D12, p. 14, 2005.

[9] D. M. Olson, et al, "Terrestrial Ecoregions of the World: A New Map of Life on Earth," BioScience, vol. 51, no. 11, p. 933, 2001.

[10] J. Chen, et al, "A simple method for reconstructing a highquality NDVI time-series data set based on the SavitzkyGolay filter," Remote Sensing of Environment, vol. 91, no. 3-4, pp. 332-344, Jun. 2004.

[11] B. W. Heumann, et al, "AVHRR derived phenological change in the Sahel and Soudan , Africa , 1982 - 2005," Remote Sensing of Environment, vol. 108, pp. 385-392, 2007.

[12] N. Pettorelli, et al , "Using the satellite-derived NDVI to assess ecological responses to environmental change," TRENDS in Ecology and Evolution, vol. 20, no. 9, pp. 503-510, 2005.

[13] L. Olsson, L. Eklundh, and J. Ardo, "A recent greening of the Sahel - trends, patterns and potential causes," Journal of Arid Environments, vol. 63, pp. 556-566, 2005.

[14] P. Hiernaux, et al, "Woody plant population dynamics in response to climate changes from 1984 to 2006 in Sahel ( Gourma , Mali )," Journal of Hydrology, vol. 375, no. 12, pp. 103-113, 2009.

[15] A. Bégué, et al, "Differences between cropland and rangeland MODIS phenology (Start-of-Season) in Mali," International Journal of Applied Earth Observation and Geoinformation, p. In Press, 2014.

[16] A. Bégué, et al, "Can a 25-year trend in Soudano-Sahelian vegetation dynamics be interpreted in terms of land use change? A remote sensing approach," Global Environmental Change, vol. 21, pp. 413-420, May 2011.

[17] B. C. Reed, et al, "Measuring phenological variability from satellite imagery," Journal of Vegetation Science, vol. 5, pp. 703-714, 1994. 